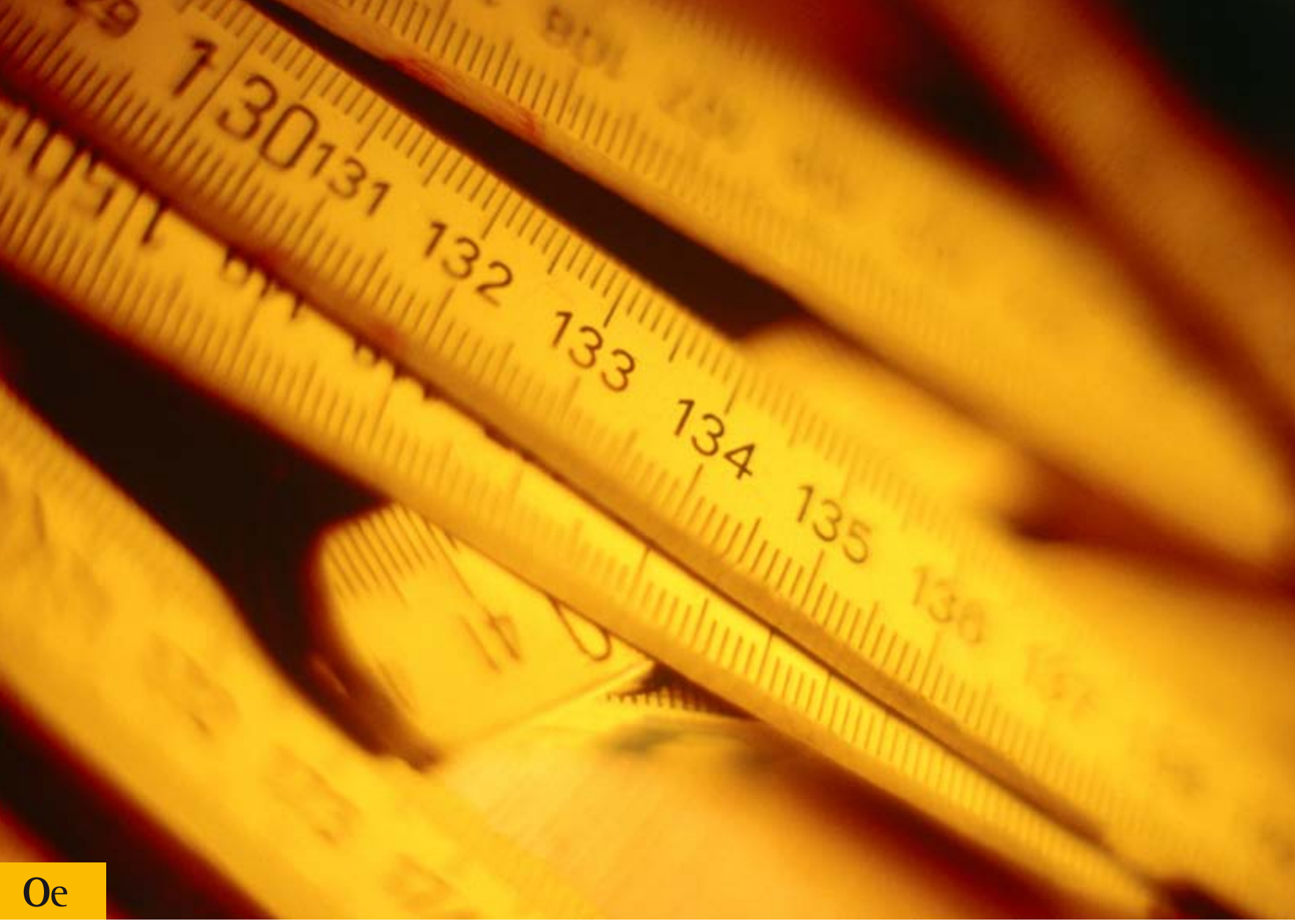

\section{Reglas de oro}

Las reglas fiscales pueden ser más efectivas para compensar los vaivenes de los precios de los commodities que la política monetaria. Sin embargo, debemos volver a tener un superávit estructural.

Por Carlos García T.*

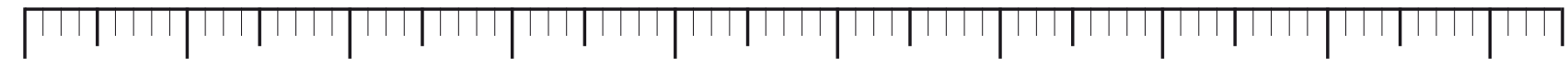

La volatilidad y el incremento del precio de commodities como el cobre, el petróleo y los alimentos básicos (trigo, maiz, arroz desafios a la estabilización macroeconóm ca. Por un lado, el precio del cobre alcanza niveles nunca antes vistos y por otro el petroleo y los alimentos siguen patrones simi-
lares. Ambos hechos pueden desequilibrar lares. Ambos hechos pueden desequilibrar nanciera y las cuentas externas no solo por su tendencia alcista, sino también porque siempre existe la posibilidad de que estos precios se derrumben o sufran fluctuaciones bruscas.

La forma de enfrentar este problema no es a través de una politica monetaria contractiva en los buenos tiempos y expansiva en los malos, sino más bien de una de tipo fiscal. En el actual escenario económico, las reglas fiscales resultan útiles para suaviza la incertidumbre que se produce en los mercados de los commodities. Una regla fisca es entendida, en sentido amplio, como una
restricción permanente y sistemática a restricción pernanente y sistemática a un limite numérico al presupuesto del gobierno Es un indicador de desempeño fiscal como el déficit, la deuda o bien uno de sus componentes. En general las reglas fiscales quedan legalmente estipuladas cuando se diseña el presupuesto del gobierno.

La evidencia internacional, especialmen en paises desarrollados, indica que la existencia de grupos de interés con objetivos mayoritariamente electorales y/o la debilldad de las instituciones han producido un sesgo hacia el déficit en las cuentas fiscaes. Incluso la discusión sobre la necesidad e reglas para la politica económica llegó válido tanto para limitar posibles actitudes

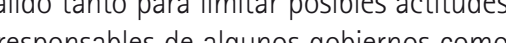
para corregir conductas racionales de estos, pero indeseadas para la sociedad. Intuitivamente el mecanismo de las reglas fiscales en economias emergentes es simple: generar ahorro (que se acumula pos buenos para usarlo en los malos. Sin embargo, la existencia de mercados internacionales de seguros incompletos hace necesario que el gobierno deba mantene permanentemente una situación superavitaria. Esto porque una economia no solo exporta commodities que están relacionados de una u otra forma con los ingresos fiscales, sino que tambièn los importa. En este sentido, una regla fiscal que acumule, por un lado, ex exceso de ingresos (comoel pensar a través de subsidios, aumentos

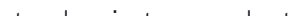
importados (como los del petróleo $y$ ali(bicos), también permite mejorar las posibilidades de éxito de la reducción de la incertidumbre.

En los paises cuyos ingresos están vinculados a la exportación de productos basicos (en el nuestro, cobre), los políticos pueden aumentar el gasto cuando el preabruptamente. Pero de esta manera la autoridad fiscal amplia (en lugar de atenuar) la volatilidad macroeconómica. De hecho, a evidencia disponible sugiere que en los paises con economias en desarrollo la maWorla de las politicas fiscales es prociclica Kaminsky, Reinhart y Vegh 2004; Talvi y (Kon 10 tanto, algunos paises Vesto no actual) de sus principales productos yo actual) de sus principales productos De esta forma

Deat esta forma, volatilidad y disciplina andisciplina gubernamental conduce no solo a fuertes ajustes fiscales, como corectamente se ha constatado en los paises desarrollados, sino también a ciclos económicos más severos debido a la conexión entre ingresos y precios de commodities. Asi, hoy una politica fiscal más disciplinada significa una menor volatilidad, tanto en las variables de politica (impuestos, gastos) como en los agregados macroeconomicos Las reglas fiscales funcionarian mejor fortalecen la stuacion superavitaria que comos dities que se importan sino también para tistadar recursos hacia los tiempos de cri-

Además, para evitar que los recursos generados por los commodities exportados se agoten debido los mayores precios de los importados, el gobierno debe recaudar escenario. Por ejemplo caida del precio del petróleo no debe trans- 
La meta del gobierno de tener un déficit estructural de $-1,0 \%$ para el 2014 deja a la economía chilena vulnerable a recesiones internacionales futuras.

Lo mismo vale si se quiere estabilizar el precio de los alimentos.

En general, el gobierno debería actuar gual que un privado que acumula ahorio preventivo para enfrentar la incertidumbre. En el caso de Chile, el gobierno debería volver a un superávit estructural de por lo menos $1 \%$ para asi asegurar mayores niveles $d$ ahorro con los que enfrentar shocks futures.

Por el contrario, la meta del gobiemo de te2014 deja a la economía chilena vulnerable ecesiones internacionales futuras.

Por supuesto, el impacto de los precios allá de la estabilización económica en corto plazo. Un exceso de divisas por exportaciones de materias primas puede causar, a la larga, una apreciación permanente y severa de la moneda doméstica respecto de otras monedas (el dólar, por ejemplo), que termina destruyendo a los otros sectores productivos, especialmente el industria Esto es lo que se conoce como "enfermedad holandesa". En este sentido, una regla fiscal puede servir para evitar este proceso a través de una reduccion paulatina de las
reservas acumuladas. te censtruidas de

te mia debe responder a criterios que maximicen el bienestar de la sociedad. Por tanto es importante que no sean reglas puramente mecánicas, que si bien son fáciles de entender por los agentes económicos, pueden producir importantes distorsiones. Por ejemplo, si bien el ahorro del gobierno es una necesidad, no tiene la obligación de ser infinito, sino que debiera alcanzar un nivel que represente las preferencias de la sociedad y que permita enfrentar los constantes vaivenes provenientes de la economía theriocional que sufre la chilena. El trabajo de encontrar estas reglas es complejo y tecnico, pero el gobierno debe financiar apropiadamente la investigación asociada No obstante lo anterior, las reglas fiscales presentan importantes desafios. En primer ugar, deben tener cláusulas de escape. En una recesión severa, pero inesperada, como a que ocurrió en 2009, no hay más camino que aumentar el gasto y evitar un desastre mayor. Paradójicamente, este tipo de necesidades urgentes hace imperioso fortalecer en tiempos de bonanza. Por tanto, los gobiernos deben soportar las presiones para gastar los fondos acumulados a pesar de las buenas intenciones argumentadas por grupos de presión (salud, educación e in-

Por otra parte, si bien las reglas fiscales son efectivas para enfrentar la falta de disciplina fiscal, no solucionan el problema que implica gastar los recursos eficienteaseguren que la inversión generada a partir de los fondos de estabilización se realice de la manera más trasparente posible y que los subsidios (como ocurre hoy con la bencina) respondan a necesidades vitales para la economia como pueden ser, por ejemplo, bienes como el trigo, el maiz, la necesidad.
Kaminski, Graciela, Carmen Reinhart y Carlos Végh, 2004. "When it Rains it Pour: Mic Policies", En Mark Gend MacroeconoRogoff, eds. NBER Macroeconomic Anmual. Cambridge, MA: MIT Press.

Talvi, Ernesto y Carlos Vegh, 2005. "Tax Policy in Developing Cocyntrices". Fourcal of Development Economics. Vol. 78, № 1 pp. 156-190.

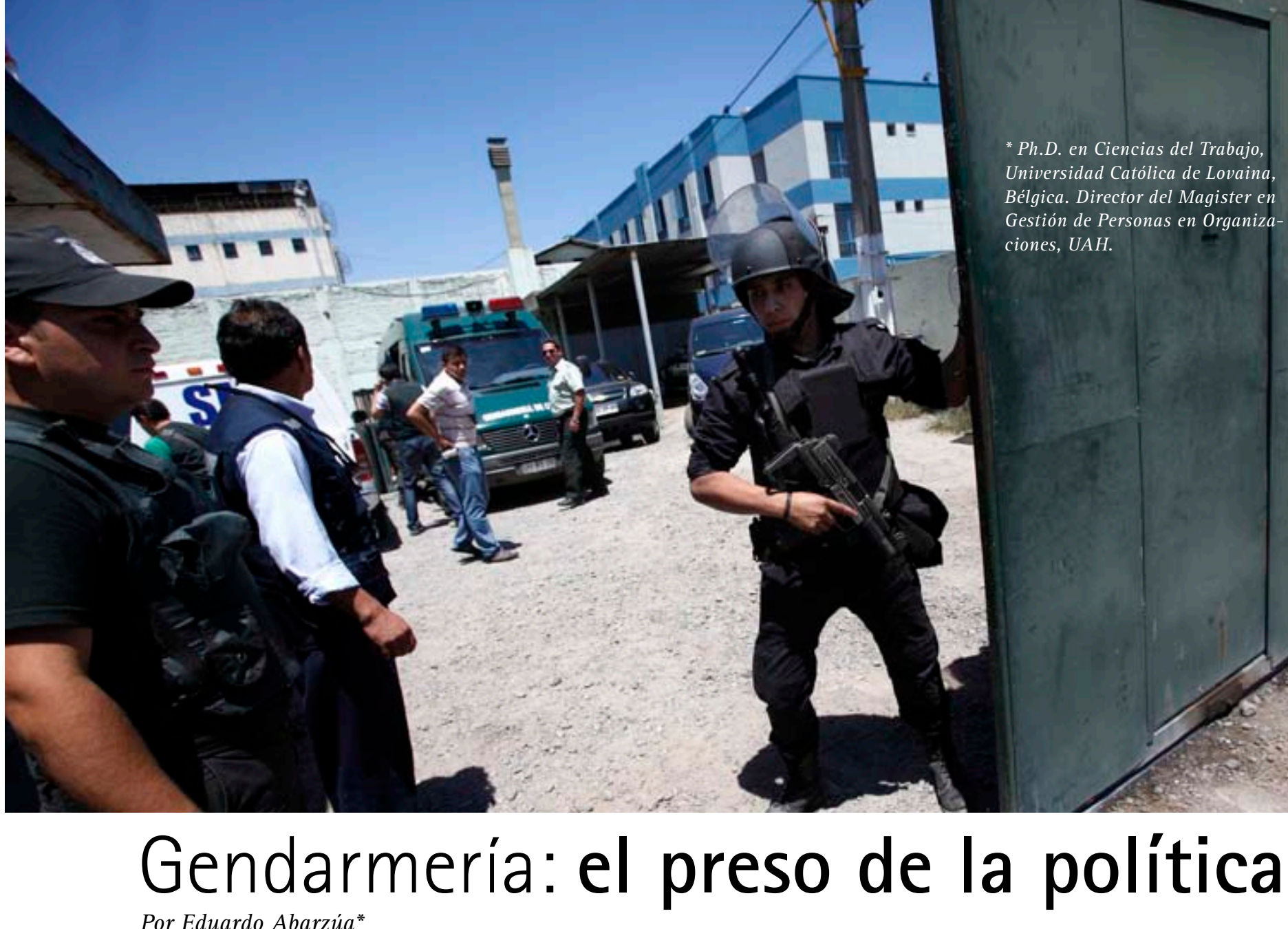
Por Eduardo Abarzía"

Desde el año 2000 todo el mundo sabe que al mejorar la eficiencia de los tribuaumentaría la cantidad de presos. Y asi ha

sido. Chile tiene el récord de ser el país de cápita de reos condenados. Por lo mismo piezas claves de la reforma de la justicia, además de los juicios orales, fueron los establecimientos penitenciarios, las salidas de adminas a la condena efectiva y los roles Para que ellos fuesen efectivos se requer un modelo organizacionctivos se requerí un modelo organizas
manos asociado

Respecto a los establecimientos penitenciarios, se requerían diez y se construyeron seis, pero hoy nadie discute el modelo de generó Respecto a los medios alterna ques el debate fue opacado por la politización del tema de seguridad ciudadana gue, con la imagen de la "puerta giratoria" de la justicia, endureció nuestras condenas Hoy descubre, como en cualquier país civilizado que encarcelar personas cuyas condenas son multas o penas que no exceden un año no es coherente con la reinserción social, que el trabajo comunitario puede ser una medida alternativa. También descubrimos que los condenados

dedica más del $3 \%$ a ellos. Para lograr te ojetivo hay que realizar cambios en profesionalización institucional tanto en los procesionalizacion institucional tanto en los el ingreso de profesionales a las tareas de gerencia penitenciaria. de administrar y vigilar nuestras con la sobrepoblación de condenados, no serán suficientes los 6000 funcionarios que, mente. Menos lo serán, si de lo único que se habla es de vigilancia y seguridad, como si ese fuera el solo fin de nuestro sistema ocupa de Gendarmeria, pues hacerlo es preocuparse de los presos, su bienestar y sus votos. La consecuencia de esto es la carencia de un modelo institucional coherente y que los gendarmes trabajan en condiciones

Sabemos qué hacer con Gendarmería. A menos desde 2006 se habla de separar las tareas de vigilancia, seguridad y contención de las labores de rehabilitación y reinsercón. Esto implica el desarrollo de un modelo de gestion que incorpore estos ultimos
roles; hoy el presupuesto de Gendarmeria

La unica novedad en la discusión sobre el

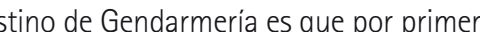
ez tenemos la oportunidad de no politizar discusión y equilibrar los principios de astigo y seguridad con la vigencia de otros principios como la reinserción, los derechos humanos de los presos, el trabajo decente para gendarmes $y$ la profesionalizacion ins政 constente co tun reforma pentitenciario coherente y sustentable. penitenciario. En un contexto de discusión politizado, salvo excepciones, nadie se pre-

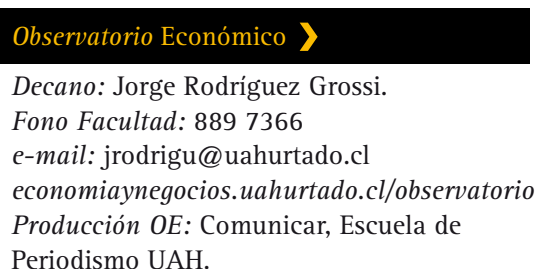

